\title{
Place references in Chinese music titles since 1912: changing patterns across regions and time
}

\author{
Xueting Hong ${ }^{1}$, Zhenfang Huang ${ }^{1 凶} \&$ Xu Huang ${ }^{1 凶}$
}

There are strong links between music and 'sense of place'. This study investigates the connotations and features of the sense of place in songs against the background of social change between 1912 and 2019 in China. From 1912 through 1949, the sense of place was chiefly patriotic. From 1950 to 1979, the influence of socialism resulted in songs that concentrated on historical sites to form place identity. After 1980, the music market influenced the writing of songs about 'place'. Since 2010, the sense of place has involved the activities of individuals and events within an area that shape the feel and impression of the place, and it is complex and plentiful. The results indicate that the relationships between people and the places they sing about become more abundant and detailed over time, along with a change from each place having a dominant style to a more diverse scenario. Before the opening-up and reform of China in 1979, the sense of place was often a shared collective memory, whereas today, the trend is towards personal songs. Additionally, sense of place is studied in regard to social processes as well as individual music pieces, and the driving force of each period is the response to basic social contradictions.

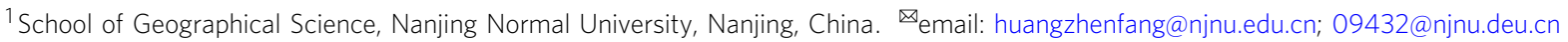




\section{Introduction}

odern media, such as music, movies, literature, and television, contains a wider range of social and cultural significance and provides valuable insights into the construction of place, identity, and even national unity. Placebased novels describe the characteristics of people and use a kind of 'lyrical narrative' to describe the place characteristics, express attachment to certain regions, and invite readers to respond positively, thus creating a sense of identity and belonging (Pocock, 1981). Films about places present specifics about a locality. For example, Sense of Place: The Fens describes the particular, special, and significant characteristics of the region in the UK through residents' daily practices, and Hong Kong films create a noisy, prosperous, and authentic image of the place as well as express the place's feelings (Cresswell, 2015; Marchetti, 2009; Burgess, 1982). Music is another art form that provides information about the place expressed as a personal emotion and idea and reflects a historical and social context (Tuan, 1977; Ryden, 1999; Gibson and Davidson, 2004; Thompson, 2006).

Songs about a place create strong images of that place (Gumprecht, 1998) and convey profound emotions related to it. Scholars believe that listening to music about 'place' helps give rise to empathy and emotional responses towards a place and signal that a person is getting to know the place. These qualities render such songs important to embody the impression and convey the writers' or listeners' emotions towards a place. Music that relates to place may offer insights into how individuals construct emotions connected to a place through the use of lyrics, melody, and timbre.

Moreover, music is always a reflection of social values (Keller, 2007) and political, economic, cultural, ethnic, and other influencing factors of the time. Thus, it is an effective tool to analyse the man-land relationship, which is shaped by and reflects sociocultural processes and ideologies. As music is an expression of culture, it is dynamically related to economic development; thus, representations of emotion about the place in songs constantly change, thereby reflecting the evolution of the society, economy, culture, and politics of an area.

The regional context is essential to the analysis of the diverse meanings of 'place' in music, as the links between places and music are different when the context and social backgrounds vary. The relationship between place and music in Chinese music dynamics has been largely unexplored in China. The territory comprising China is vast, and the nation has a long history; hence, there is a rich and diverse body of music with place names. Furthermore, as the times change, the places in songs focus on diverse regions and show different connotations. China experienced a rapid economic and social transformation between 1912 and 2019. There was a profound social change from wartime to peacetime and in the transition from a collective to a socialist market economy.

This study examined the concept of 'sense of place' with regard to the nonlinear dynamic process of social evolution over time. The purpose of our investigation was to explore the connotation and meaning of place in songs within the constantly changing social background throughout history. We explored how variations in the sense of place are conveyed and examined shifts in the characteristics of regions in music while emphasising the historical characteristics of divergent periods against the background of social change in China. It is unsurprising that many geographers have addressed the role of songs in the sense of place and to reassemble connections to places and even nations. We examined place references in songs titles and emphasise connections with social background change. The results confirm that the sense of place is individual but is also constructed by social change as evidenced in China.

\section{Literature review}

A sense of place can be considered as a collection of symbolic meanings, attachment, and affection associated with a spatial setting held by an individual or group. Local residents gradually develop a sense of place through their long-term human-to-land interactions. The meanings that individuals and collectives ascribe to a place are reflections of the cultural and social background. A sense of place that is constantly strengthened, reinforced, shaped, and widely accepted becomes a collective experience of its residents (Greider and Garkovich, 1994; Stokowski, 2002).

The theory of constructivism asserts that the meaning and value of place are built over time; thus, the sense of place is discursively and dynamically manipulated towards the collective or the individual (Brown and Perkins, 1992; Devine-Wright and Howes, 2010; Feldman, 1996). Lee (1972) argued that place meanings are also socially constructed and shared by members of a cultural group. Halbwachs (1992) proposed that memories of individuals are framed and shaped by the collective representation of the past shared within their group (Liu and Hilton, 2005; Misztal, 2003). Thus, the sense of place constitutes not only the feelings of individuals but also the influence of external social contexts, thereby producing a collective sense of place (Jenkins et al., 2016).

Music can express individual or collective feelings and awaken memories when the listening involves one's experiences and the listener creates images connected to the sound. The music triggered by social events about a certain place can be shared amongst a group of people; accordingly, it can be regarded as an expression of the collective perception of such places. The electronic medium (playing music over radios or via recordings) turns the original private situation into a public one. Thus, a sense of place conveyed through songs and formed without direct experience of the relevant place becomes a part of collective memory-building due to widespread singing and listening to the music. It also becomes personal through multiple experiences of being in the place (Lewicka, 2011). Private places tend to generate a personal sense of place, while public places are more likely to form a collective sense of place. The sense of a city, region, or nation is constructed through the process of feeling the physical and cultural characteristics shared by the collective. In turn, collectivism shapes how people regard and emotionally connect with a place (Roccas et al., 2008).

A sense of place is determined by three components: social interactions, the physical setting, and human psychological processes (Stedman, 2003). Some places with similar characteristics induce similar psychological processes in people. After a long time of being engaged with a place, a strong or positive place attachment creates a sense of rootedness, which is a deep, single emotion providing a source of identity. There is no single sense of place, for each person's sense of place is unique. In situations when individuals' sense of place presents certain characteristics influenced by the background of government control or mainstream culture, the sense of place tends to be dominative.

Many scholars, focused on mobility in modern societies, emphasise the unsettling impact of its effects and the feeling of insecurity it can produce. Diverse forms of mobility contribute to the formation of emotional bonds between people and places. Gustafson (2009) suggests that highly mobile individuals will produce stronger emotional bonds with larger place scales without reducing the sense of place of a living city. Sense of place is often awakened by the mobility of the individual because a growing sense of one's place emerges when mobility increases. That is to say, the sense of place is constantly developing and dynamic against the background of the times. In more complex 
social contexts, the relationship between man and land has changed from a dominative and relatively rigid concept to a diverse one, dynamic with the process of modernisation and globalisation.

Music, as an expressive project that holds a variety of possibilities for geographical study, spurred a series of debates and a growing body of scholarship (Bennett, 2017; Byklum, 1994; Canova, 2013; Carney, 1998; Milburn, 2019; Revill, 2005) starting in the 1970s. Kearney (2010) argued that music geography could be divided into two traditions of cultural geography. American scholars concentrated on patterns of location, musical landscapes, and the diffusion of music, inspired by the so-called Berkeley School that was spearheaded by Carl Sauer (Carney, 1987; Connell and Gibson, 2004), while a British-based discourse is more concerned with spaces, networks, and contexts for the performance and consumption of music and identity (Leyshon et al., 1998; Attali, 1985). The study of music geography in China follows the paradigm of Western scholars. The research on the American genre focuses on regional music characteristics (Qiao, 1998). Ma and Deng (1995) analysed the geography and cultural basis of the formation of Chinese folk song areas, pointing out that music is a way to express human thoughts and emotions and that different geographical environments produce different groups of people and different styles of music performances. Qiao (1998) considered that the objective existence of a geographical environment and its spatial differentiation is the indispensable prerequisites for the formation, development, change, and regional differentiation of Chinese music. In contrast, research on the British genre emphasises spatial production, place attachment, and music identity (Liu and Cai, 2016, 2014). Liu and Cai (2016) analysed how Guangzhou's live popular music is shown in the identities of different people. Lin (2019) analysed collective memory and sense of place based on Taiwan's Hakka Music and holds that Hakka Music can reconstruct national memory and serve as a carrier of collective identity and memory. Some additional Asian scholars have made achievements in this field (Kong, 1995). Japanese scholar Yano (2003) also discussed the nostalgia in popular music that is built upon collective memory. The terms used in the lyrics of a piece of music about a place are worth studying, as they convey the creator's experiences, perceptions, and emotions towards the place, and the audience perceives and interprets those lyrics (Byklum, 1994). Long and Collins (2012) explore their mapping practices regarding Birmingham's music scene and the soundscapes of the popular music map. Wood and Gritzner (1990) summarise the image of place through a country's music lyrics for geographic study. The geographical features in music reflect the attributes of a place; simultaneously, the geographical features of the place also shape the music.

As an important channel of expression of an individual's understanding and experience of their environment, music has the ability to move people; it can also be used as political propaganda (Street, 2003). Sociologists have explored music's function in promoting social change (Roberts, 2001). Others have investigated the use of music to stir up national political consciousness and contribute to transitions within political movements. Fung (2007) considered that before the emergence of modern popular music, music in China was used to serve political purposes and resonated with the national ideologies. As Street (2003) revealed, music can be a powerful weapon because it works directly on our emotions and thoughts, as evidenced by the attempts of some politicians to utilise music's propaganda effects to increase youth participation in elections.

Scholars worldwide have also investigated the relationship between music and culture. There are numerous topics within the main concept of music and culture. For example, Clayton (2013) debates the interrelationship between music and culture in society and throughout history. Gritzner (1978) examined the idea that 'country music', which is identified as a native art form in American culture, is a reflection of the culture, as the music tends to provide satisfaction and entertainment for a large audience. Bennett (1999) draws attention to the relationship between youth culture and music; based on an empirical study of British dance music, he proposed that it is used as an alternative tribal subculture. He also attempts to regard the reworked hip hop as a localised cultural expression of youth in Frankfurt (Bennett, 1999). Scholars have already established that musical practices are usually dependent on social, economic, and cultural interactions. Thus, music can be seen as a narrative of social history based on historical perspective.

Music can be regarded as the primary material for understanding the character and identity of places (Kong, 1995). The feeling of the place is expressed and conveyed through the lyrics and compositions; as the listener perceives the sense of place and empathises, the composer's sense of place becomes their own (Connell and Gibson, 2003; Leyshon et al., 1995). Gumprecht (1998) points out that many musical artists have produced work that evokes a strong sense of place-for example, the Beach Boys and Eagles helped create a sense of place for Southern California that still defines the region in the eyes of many. Many studies have concentrated on these perspectives, including how, within a given place, various genres such as rock, folk, rap, and popular music are all able to evoke different emotions and bonds with the place (Connell and Gibson, 2003; Kong, 1995; Revill, 2000). Kong (1995) explored geography and popular music in Singapore and showed that lyrics conveyed a sense of place and reflected a distinctive Singaporean spirit and identity.

Music plays an important role in producing a sense of place by giving listeners a sense of belonging (Hudson, 2006). Hudson (2006) emphasised the strong links between music and a sense of place-both historical and contemporary. The increased attention to music relates to its important everyday role in the social construction of places and identities (Morgan, 2001; Kearney, 2009). A sense of place illuminates the emotions and cognitions connected with the place where an individual lives, and it is influenced not only by personal practice but also by the physical context of socio-cultural settings (Stokowski, 2002; Williams, 2002). In the process of social development, individuals are under the invisible control of their social background, and their sense of place will also show certain characteristics due to the influence of that background.

Music is also an effective tool for analysing the sense of place, which is shaped by and reflects the relevant historical period. With changes in a social context, the sense of place conveyed through songs is influenced by social conflicts, which are reflected as social conditions that determine the content of the sense of place in music composition. The sense of place is further cultivated through daily-life practices and social contexts; various types of emotions are associated with places based on their representation in songs.

The formation of a sense of place is also considered in the process of social construction (Kyle and Chick 2007; Stedman, 2003), and the connotation of the sense of place changes with the social background through long history (Harvey, 1996, p. 303). Figure 1 presents a sketch of the sense of place with songs from 1912 to 2019 in China. It is divided into four time periods. The abscissa represents the collective and individual social characteristics as well as a sense of place, and the ordinate represents diversity and dominative social characteristics as well as a sense of place. In 1912-1949, the sense of place is collective and diverse; it, thus, becomes dominative. When it comes to 1979, the sense of place tends to be individual, and in 2010-2019, it is diverse and individual. Of course, this kind of representation is a simplification 


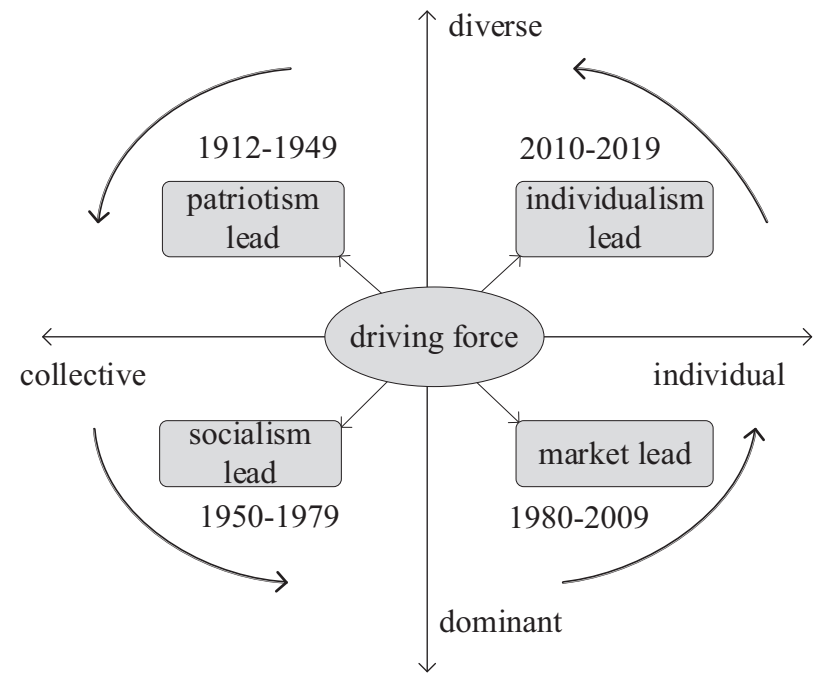

Fig. 1 Conceptual framework and transaction of sense of place.

Conceptual framework and transaction of sense of place indicate that as the social situation changes, the characteristics and connotations of the mainstream sense of place in society will change accordingly, shifting from collective to individual and from dominant style to the diverse scenario.

of the complex phenomenon of sense of place. Nevertheless, we argue that such representations may indicate the characteristics of a sense of place in each period and highlight dependencies and changes between characteristics.

The period from 1912 to 1949 is a history of the Chinese people's exploration of the road to national salvation, freedom, and democracy. A collective sense of place was stimulated by the principal contradiction of society. During the Anti-Japanese War and Civil War, a sense of place was mainly encouraged through patriotism. From the establishment of the People's Republic of China (PRC) to the reform and opening-up, pressures from economic construction and the strict hukou The household registration system restricted the mobility of individuals, and the sense of place was restricted due to the constraints of socialism. From reform and the opening-up to 2009, the audio-visual products were physical (e.g., CD and tape), and the sense of place in music was based on the significant influence of the music industry and market demand. After 2009, the sense of place represented in music became more subjective, personal, and fragmented, indicating the influence of individualism. There are also differences in the main driving forces of each period. Meanings of place are functionally valued rather than merely formed individually and are based on power relations that affect interpretation and meaning-making. Power also exerts itself more subtly: even our experiences are not freely chosen but are influenced by the current configuration of social conditions and forces (Pred, 1984; Stokowski, 2002; Zukin, 1991). The sense of place in Chinese music shows a change from collectivism to individualism and from dominant style to a more diverse scenario, based on the value system reflected in different economic, social, and cultural backgrounds.

\section{Methodology}

Data sources. Place-related music is one medium for expressing the sense of place, and such songs are the primary data sources for the geography and content analysis of the sense of place. A song's title is often simultaneously a summary, refinement, and sum of the lyrics, explaining the basic connotation of the song. To ensure the objectivity of the data source and for the geographic visualisation, songs titles containing place names were selected for the study. We selected songs that included place names in their titles and supplemented them with songs that express a sense of place. In terms of data sources, place-related music in modern times (1912-1979) is discussed in books such as The History of Modern Music (Wang, 2009) and 90 Years of Songs (Lei and Wang, 2011). The music of this period is collected mostly in books. We used NetEase Cloud Music ${ }^{2}$ and QQ Music ${ }^{3}$, the main music platforms in China, to search contemporary music (1980-2019) by song title for city and place names. With the richest music copyright, they are the leaders in market share and contain various genres of music. We manually searched music titles for specific cities using prefecture-level ${ }^{4}$ cities as the unit, then entered China's 293 prefecture-level cities, 30 autonomous prefectures, seven regions, and three leagues, as well as 'Hong Kong', 'Macao', and 'Taiwan', into the online music platform. Considering the copyright restrictions or censorship by government agencies, this research also pays attention to some songs that express a sense of place but are blocked online. The style of music is not limited; the main music styles used for our in-depth study included popular music, folk songs, rock, R\&B, hip-hop, and so on, provided on the online platforms. We considered the Chinese language only, including various dialects such as Cantonese.

Given that sense of place differs across different backgrounds, the feelings of emotional connection between human beings and the land were analysed in different periods and were divided based on the major events in the society of each period. From 1912 to 1949, China experienced the establishment of the Republic of China (1912), the Anti-Japanese War (1937-1945), and the Civil War (1945-1949). In 1949, the PRC was founded, ending the melee state in China. The period between 1950 and 1979 was the primary stage of socialism after the establishment of the PRC. During this period, society experienced social campaigns such as the 'Great Leap Forward' (1958-1960), the 'Cultural Revolution' (1966-1976), and the 'send-down' policy (1967-1968), and people were subject to severe thought control. After the commencement of the opening-up and reform policy in 1979, the economy and culture changed significantly and flourished. After 2010, in the era of highly developed Internet and online music commerce, individuals increasingly released independent music through electronic media, and the amount of online music in China increased dramatically. Since 2010, the Ministry of Culture has issued an annual report on the development of China's online music market ${ }^{5}$. With comprehensive consideration of the main social phases and the number of musical pieces with place names in their titles, we investigated four time periods, 1912-1949, 1950-1979, 1980-2009, and 2010-2019, to analyse the sense of place in different periods through songs. The data are not evenly divided among these periods because there are differences in the number of local music pieces in different eras. After 2010, in view of the developed Internet and more common individual mobility, a great amount of music-related to place was generated and can be found on online music platforms. The deadline for data collection was March 29, 2019. A list of a total of 3758 song titles is provided, and the number of samples obtained for each period is shown in Table 1.

Research methods. In the current study, the spatial distribution and agglomeration of the sense of place are described using ArcGIS and the longitude and latitude of places referenced in song titles. Kernel density estimation estimates the value of probability density of a raster pixel using neighbourhood analysis based on the distance decay function, which can reflect the 
Table 1 Number of songs with names of places for each period of time.

\begin{tabular}{llll} 
Time & Number & Proportion (\%) & Representative works \\
\hline $1912-1949$ & 64 & 1.70 & Nanniwan; The Yellow River Cantata; On the Taihang Mountain \\
$1950-1979$ & 130 & 3.46 & Golden Hill in Beijing; Learn from Dazhai and chase Dazhai \\
$1980-2009$ & 566 & 15.06 & Shanghai; To Taipei to see the rain in winter \\
$2010-2019$ & 2998 & 79.78 & Nanjing Nanjing; Lanzhou, Lanzhou; Going to Dali
\end{tabular}

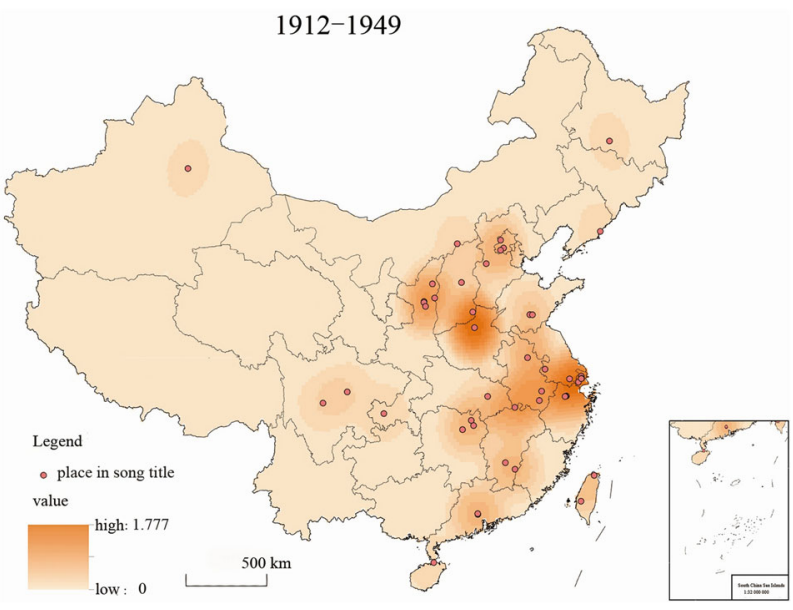

Fig. 2 Kernel density estimation of place in music in 1912-1949. Kernel density estimation of place in music titles from 1912 to 1949 indicates that the darker areas are distributed primarily in the Yellow River Basin and the Yangtze River Delta region. These places are often referred to in song titles, forming a cluster.

location, shape, and size of distribution with the help of a probability distribution map (Peng et al., 2016). The formula is as follows:

$$
f(x)=\frac{1}{n h^{2} \pi} \sum_{i=1}^{n}\left[1-\frac{\left(x-x_{i}\right)^{2}+\left(y+y_{i}\right)^{2}}{h^{2}}\right]^{2} .
$$

$h$ is the threshold; $n$ is the number of points within the threshold; $\left(x-x_{i}\right)^{2}+\left(y+y_{i}\right)^{2}$ measures the coordinate deviation between points $\left(x_{i}, y_{i}\right)$ and $(x, y)$. In a kernel density map, the darker the colour, the denser the distribution. Following kernel density analysis (Figs. 2-5), we summarised the largest cluster, the reason for the cluster, and contents of sense of place. To reveal the characteristics of a sense of place in different periods, the songs' names and lyrics were discussed in detail.

The names of songs that express the sense of place were analysed by the term frequency-inverse document frequency (tf*idf) method to identify high-frequency words. Tf*idf was proposed by Salton and Buckley (1988) to represent text features in vector space considering the word's frequency in the document and its popularity in the corpus. It is one of the most commonly used terms in weighting schemes defined as

$$
T f^{*} i d f=t f_{i j}{ }^{*} \log \left(\frac{N}{d f_{i}+1}\right)
$$

where $T f_{i j}$ measures the term frequency of word $i$ appears in document $j$, and idf can be interpreted as 'the amount of information' in conventional information theory, given as the log of the inverse probability (Aizawa, 2003; Van Zaanen and Kanters, 2010; Kim et al., 2019), The parameter $d f_{i}$ measures the number of documents in which word $i$ appears. A word is considered important if it appears frequently in one document and rarely in the corpus. The 76 corpus' works were collected from the modern Chinese corpus provided by the website of the Ministry of Education's Language and Character Application Research Institute using the keywords economics, politics, sports, transportation, art, education, computers, military, environment, and medicine. The text of song titles was analysed using $\mathrm{tf}^{*} \mathrm{idf}$ for different periods. The words that appeared in the titles were sorted according to the tf*idf values for the different periods and are described in Tables 2-5.

\section{Results}

The sense of places in 1912-1949. The kernel density map showed that from 1912 to 1949, two cluster areas-the Yellow River Basin and the Yangtze River Delta region-formed the core (Fig. 2).

During the Republic of China period (1912-1949), China was weakened by foreign and civil wars. From 1912 to 1936, during a period of high prosperity in the Shanghai concession, Shanghai became the birthplace and focus of Chinese popular music, appearing in songs such as 'Nightlife in Shanghai', 'Shanghai Miss', and 'Shanghai Sailing'. In 1937, the anti-Japanese War broke out, and the number of song expressions of place reached a peak. There are songs about significant places in the anti-Japanese War, such as 'Yellow River Cantata', 'On the Taihang Mountain', 'Defending the Lugou Bridge', 'On the Jialing River', 'Ballad of the Great Wall', and 'Armed Defence of Shanxi'. 'Yellow River Cantata', which was sung by people struggling in the early 1940s, had the following lyrics: The wind is roaring, the horse is roaring, the Yellow River is roaring, the Yellow River is roaring, the western hills of the river are so high, the eastern and northern sorghum of the river are cooked, there are a lot of anti-Japanese heroes in the mountains, the guerrilla in the Qingsha tent is a hero, picked up a soil gun and a gun, wielding a sword and spear. The Yellow River is often a metaphor for the nation, its beauty, power, and hardships (Tuohy, 2001), and the associated emotion is used to praise the history of China, and the persistent struggles of Chinese citizens (renmin). The lyrics of 'On the Taihang Mountain' evoke similar shared emotions and embody the heroic and tenacious revolutionary spirit of the people and soldiers of Taihang Mountain: Mother told her son to fight in Japan, the wife sent her husband to the battlefield, we are on Taihang Mountain, we are on Taihang Mountain. These songs were aimed at mobilising the masses to act as one against a foreign enemy and to foster concerted mass action.

From 1945 to 1949 , most songs encouraged people to win the War of Liberation. Northern Shaanxi was not only a revolutionary base but also a prosperous place for the revolutionary cultural mass art movement during the War of Liberation, with folk music such as 'Yan'an' and 'Nanniwan'. In the Lu Xun Academy of Arts, briefly 'Yan'an Luyi' (built in 1938), musicians modified local folk music with new ideological content, and then brought it back to the people to spread it, organising various types of music groups to promote socialism (Holm, 1984, p. 32). There were songs such as 'We Want to Protect the North of Jiangsu' and 'Farewell to Southern Anhui', forming a spatial agglomeration in the Yangtze River Delta. Southern Anhui and Jiangsu provinces were important regions for the New Fourth Army during the 
Table 2 Keywords of sense of place: 1912-1949.

\begin{tabular}{|c|c|c|c|c|c|}
\hline Key words & TF-IDF & Key words & TF-IDF & Key words & TF-IDF \\
\hline Yellow River & 10 & remote & 2 & Armed & 2 \\
\hline defend & 5 & Mizhi & 2 & Flag & 2 \\
\hline Shanghai & 4 & Yanshui & 2 & Huangqiao & 2 \\
\hline Fengyang & 4 & Yan'an & 2 & Yellow water & 2 \\
\hline Taiwan & 3 & Shan Gan Ning & 2 & Jinchaji & 2 \\
\hline Soviet Area & 3 & Great Wall & 2 & Gondolier & 2 \\
\hline Suzhou River & 3 & Yangtze & 2 & Guangzhou & 2 \\
\hline roar & 3 & Sun Zhongshan & 2 & Armed & 2 \\
\hline girl & 3 & Leifeng Tower & 2 & Wu Song & 2 \\
\hline Wannan & 3 & Liberated area & 2 & Border area & 2 \\
\hline West Lake & 3 & Yalu River & 2 & Nanniwan & 2 \\
\hline Yangtze River & 3 & Lugou Bridge & 2 & Taihang Mountain & 2 \\
\hline Jiangdong & 2 & Sanyuanli & 2 & Shanxi & 2 \\
\hline West Gate & 2 & Songjiang & 2 & Minjiang river & 2 \\
\hline
\end{tabular}

Civil War. There were a few place nodes in China, forming an intensive area comprising the Yangtze River and the Yellow River. The keywords for this period included 'Yellow River', 'defend', 'Shanghai', and 'Yangtze' (Table 2).

Between 1912 and 1949, the country was turbulent and unstable, and people focused on the survival of the nation. The songs during these periods conveyed attachment to one's native land and unwillingness to leave it, given that land resources are the source of human production, as depicted in the lyrics of 'On the Jialing River': That day, the enemy hit my village, and I lost my farmhouse, family, cattle, and sheep. Now, I wander on the Jialing River. I seem to smell the fragrance of the soil in my hometown, the same flowing water, the same moon, I have lost all my laughter and dreams. The mobility generated by the war significantly inspired people's sense of place. Awareness of sense of place is often unselfconscious, but when land is perpetually invaded, and the invasions threaten the local meaning and identity of the original state, sense of place will be extremely strong and result in xenophobia (Tuan, 1977). It shows a strong rootedness in this period of crisis for China.

Moreover, there are numerous folk songs named after the wellknown mountains and rivers in this period. Rivers such as the Yangtze and the Yellow River symbolise the Chinese nation and are closely related to most people's daily lives; such geographical elements can awaken collective memory and patriotic feelings $(\mathrm{Li}$, 2008). During this period, the emotional connotations of people and places were mostly patriotic, demonstrating attachment to and dependence on hometown and heritage. The sense of place is also indicative of national consciousness and featured dominantly. As O'Connell (2011) notes, the music reflected a wider deliberation about the place and national identity during wartime; there is no doubt music played a significant role in China's peace process. In the political realm, music was accorded a significant place in forming a more coherent national and social identity.

The sense of places in 1950-1979. From 1950 to 1979 , the sense of place kernel density map is concentrated primarily in Beijing, Shanxi, Shaanxi, Hunan, and Jiangxi provinces (Fig. 3).

The founding of the PRC in 1949 ensured the people's position as heads of the country within the socialist system and enabled more peaceful living. Many songs from this time praise Beijing and national leaders, especially in ethnic minority areas (Croizier, 2010 , p. 175). Socialist construction remained central in the musical rhetoric of the PRC, as illustrated by the lyrics of 'There is a Golden Sun in Beijing': Beijing's Jinshan mountain shines everywhere, Chairman Mao is the golden sun, how warm and kind, light up the hearts of our serfs, we are walking on, on the

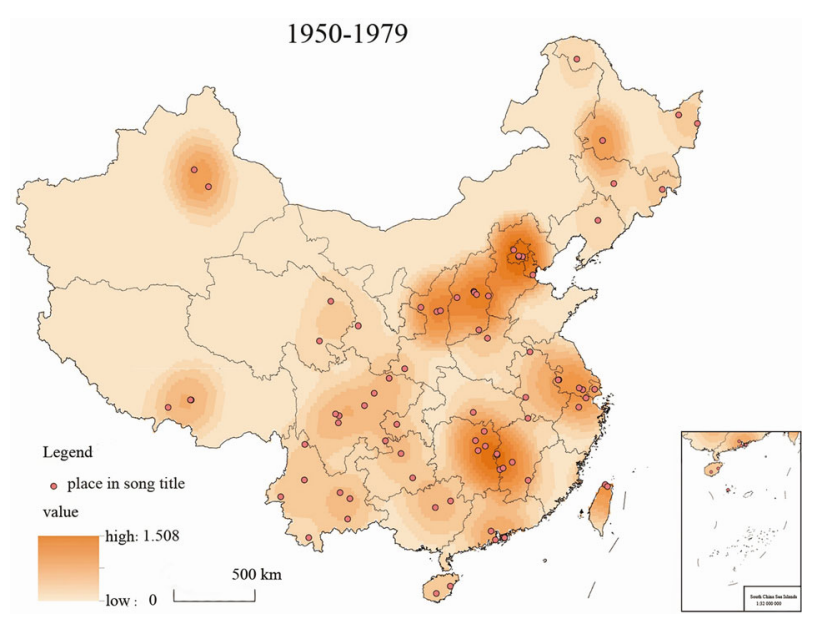

Fig. 3 Kernel density estimation of place in music in 1950-1979. Kernel density estimation of place in music titles from 1950 to 1979 indicates that the darker areas are distributed mainly in the Beijing, Shanxi, Shaanxi, Hunan, and Jiangxi provinces. These places are often referred to in song titles, forming a cluster.

road to socialist happiness. The song reflects the people's recognition of and gratefulness for Beijing because the great leader is in Beijing and the subject of a personality cult. The Great Leap Forward (1958-1960) movement launched in 1958 in China to spur economic development pursued telescoped but blind development. Some of the songs are about typical deeds; these include popular songs such as 'The Road of Daqing is Wide' and 'Dazhai People's Heart Goes to the Red Sun', which led people nationwide to form a strong place identity and attachment to these places. Yan'an, located in northern Shaanxi province, and Jinggangshan, in the eastern Jiangxi Province, were important revolutionary bases for the Chinese to sing about, as represented in songs such as 'Back to Yan'an', 'Jinggangshan', and 'Yan'an Song'. The revolution songs would become heavily promoted by the state (Liu, 2010). The spread of the flames of the war coincided with the kernel density map of 1950-1979.

The campaign 'send-down' required intellectual youth to go to the countryside and be re-educated about the poor and the peasants (Bonnin and Horko, 2013). This move was initiated by Mao gave rise to a group of 'educated youth' songs (Bryant, 2005). These intellectuals missed their hometown in the countryside and produced music such as 'Farewell to Beijing' and 'Nanjing, my hometown'. The lyrics of 'Nanjing, my hometown' express the hardship of educated youth leaving their hometown: White clouds 
Table 3 Keywords of sense of place: 1950-1979.

\begin{tabular}{|c|c|c|c|c|c|}
\hline Key words & TF-IDF & Key words & TF-IDF & Key words & TF-IDF \\
\hline Beijing & 15 & Tiananmen Square & 3 & Tibet & 2 \\
\hline Dazhai & 9 & Taipei & 3 & Fish and rice & 2 \\
\hline sun & 7 & Turpan & 3 & oil & 2 \\
\hline Jinggangshan & 7 & Hong Kong & 3 & Wide roads & 2 \\
\hline Daqing & 7 & majestic & 3 & War song & 2 \\
\hline Yan'an & 9 & great & 2 & motherland & 2 \\
\hline home & 6 & Xinjiang & 2 & Best wishes to red army & 2 \\
\hline frontier & 6 & hometown & 2 & People's Liberation Army & 2 \\
\hline Nanjing & 5 & Educated youth & 2 & Zhongnanhai & 2 \\
\hline singing & 5 & Taihu & 2 & Liuyang River & 2 \\
\hline Shaoshan & 5 & Sons and daughters & 2 & Farmer & 2 \\
\hline girl & 4 & Dabie Mountains & 2 & hero & 2 \\
\hline Chairman Mao & 3 & worker & 2 & Zunyi & 2 \\
\hline red flag & 3 & conference & 2 & Heart & 2 \\
\hline
\end{tabular}

are flying in the blue sky, the beautiful Yangtze River bank is lovely, Nanjing is an ancient city, my hometown. Ah, the rainbow bridge, go straight to the sky and cross the Yangtze River, at the foot of the majestic Zhongshan is my lovely hometown. Say goodbye to mom, goodbye my hometown. The keywords in these periods were 'Beijing', 'Dazhai', 'sun', 'Jinggangshan', 'Daqing', 'Yan'an', and 'home' (Table 3). From 1950 to 1979, the country had a hukou system, which restricted the mobility of individuals between urban and rural areas. During this period, the sense of place reflected the collective emotions of places with historical significance, such as Beijing, Yan'an, Zunyi, Jinggangshan, and Daduhe. People had a strong reverence for Beijing and Hunan province, given that these places were, respectively, the residence and the birthplace of Chairman Mao, who was the subject of strong worship during this period. Adoration for Daqing and Dazhai, constructed on these cities, became the model for industry and agriculture, which drove the motivation for economic development under the campaign of 'Great Leap Forward'. The sense of place was formed owing to the interaction between the physical practice and the social process of the place. Most songs before 1979 demonstrate ideological value; Chinese people are familiar with the twin functions of aesthetic enjoyment and ideological instruction in music (Perris, 1983). The sense of place expresses the praise, gratitude, and passion for revolutionary and economically developed places; it is characterised by dominative. The main driving force in this period is socialism because the meaning of the place, which is represented in songs, is constructed under socialism.

The sense of places in 1980-2009. From 1980 to 2009, places evoking emotions were concentrated primarily in areas such as Beijing, Yangtze River Delta, Pearl River Delta, and Lhasa (Fig. 4).

Owing to its embrace of market economics in the last couple of decades, the music market has been influenced by the inflow of commodity music from the thriving cultural markets of Hong Kong and Taiwan, thus causing the spatial agglomeration around the Pearl River Delta. Guangzhou was one of the first cities to access Hong Kong's popular music industry and became the main centre of popular music production on the mainland due to its geographic advantage. However, the music of Hong Kong and Taiwan are greatly influenced by globalisation and Western popular music. Beijing is the political, economic, and cultural centre of China, with an important music industry; thus, it became a hotspot for songs about places related to it during this time. Date-dense areas have been formed in the Yangtze River Delta due to the advantages of the dense distribution of cities like Shanghai, prosperous economy, and culture of tradition and

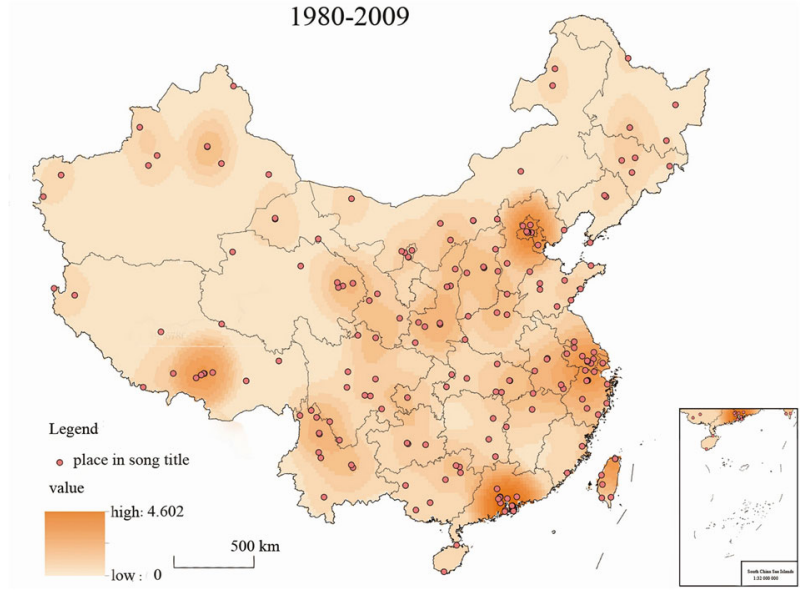

Fig. 4 Kernel density estimation of place in music in 1980-2009. Kernel density estimation of place in music titles from 1980 to 2009 indicates that the darker areas are distributed primarily in the Beijing, Yangtze River Delta, Pearl River Delta, and Lhasa. These places are frequently referred to in song titles, forming a cluster.

music. Given the special terrain and Buddhist culture of Tibet, it is reasonable for the ancestors of the Tibetan people to use mountains, water, and animals as their main objects of worship. There are also many places and natural elements in songs, such as 'Animaqin Snow Mountain', 'Qinghai-Tibet Plateau', and 'The Yarlung Zangbo River'. These are some of the lyrics from 'Qinghai-Tibet Plateau': I see mountains after mountains, connected by mountains, Yalaso, that is the Qinghai-Tibet Plateau. After the reform and opening-up policy, the aesthetic characteristic of places became more apparent in the experience and concern for the physical characteristics of those places. The most prominent places are indicated in our $\mathrm{TF}^{*} \mathrm{IDF}$ keywords: 'Beijing', 'Taipei', 'Hong Kong', 'Shanghai', and 'Lhasa' (Table 4).

From 1980 to 2009, after the reform and opening-up, with the development of the socialist market economy system, music production was mainly concentrated in Hong Kong, Taiwan, and Beijing. The 1980s were the golden age of Hong Kong music (Ho, 2000). Individuals showed a mobile tendency, and industrialisation spurred great changes in rural areas and towns. Individuals could not adapt, and there was a great need to express a sense of place. Production methods became more diverse, and the close ties between humanity and place were broken, as depicted in the lyrics of 'Lugang Town' (1982, Dayou Luo): Taipei is not my 


\section{Table 4 Keywords of sense of place: 1980-2009.}

\begin{tabular}{|c|c|c|c|c|c|}
\hline Key words & TF-IDF & Key words & TF-IDF & Key words & TF-IDF \\
\hline Beijing & 34 & magical & 7 & Wenzhou & 5 \\
\hline Taipei & 31 & Tibet & 7 & Xi'an & 5 \\
\hline Hong Kong & 18 & Guilin & 6 & Scenery & 5 \\
\hline Shanghai & 12 & Changan & 6 & hometown & 4 \\
\hline home & 12 & Qinghai & 6 & Kunming & 3 \\
\hline story & 11 & Jiuzhai & 6 & impression & 3 \\
\hline beautiful & 11 & Yellow River & 6 & Suzhou & 3 \\
\hline Macao & 10 & rose & 6 & Potala & 3 \\
\hline Lhasa & 10 & Hangzhou & 6 & Dunhuang & 3 \\
\hline Xinjiang & 10 & Nanchang & 5 & Lanzhou & 3 \\
\hline Huangshan & 9 & love & 5 & Tianshui & 3 \\
\hline Lijiang & 9 & $\begin{array}{l}\text { Dabie } \\
\text { Mountains }\end{array}$ & 5 & Gulangyu & 3 \\
\hline Guangzhou & 8 & Lan Kwai Fong & 5 & Qinghai Lake & 3 \\
\hline girl & 8 & Shigatse & 5 & Huizhou & 2 \\
\hline
\end{tabular}

home, my hometown has no neon lights, the streets of Lugang, the fishing village of Lugang, the people burning incense in the Matsu temple. Significant changes in place, such as the disappearance of a pub and increased neon lights, may have great symbolic meaning for individuals and can result in a disruption of the individual-place bonds (Di Masso et al., 2011; Di Masso and Dixon, 2015). When the places for which people have affection are destroyed, a sense of loss emerges, and 'the sense of loss that they express is not only a loss of place but also, more profoundly, a loss of self (Dixon and Durrheim, 2000, p. 36). The loss of an important place can disrupt place bonds (Bonaiuto et al., 2002; Devine-Wright and Howes, 2010; Inalhan and Finch, 2004), triggering feelings of grief (Chow and Healey, 2008). The lyrics of 'Wedding Card Street (Xitie Street)' demonstrate this phenomenon: The original wedding invitation gold leaf printed on him, frame the wall of wedding photos, and all the beautiful old days, tomorrow will be demolished. The song was written for Hong Kong and represents nostalgia and the 'old city complex' that had been swallowed up by modern civilisation for many Hong Kong people. Moreover, there was a more abundant sense of place and more places for generating emotional connections. The concept and identity of places tended to shift from a dominant style to a more diverse scenario. Although the songs indicate the daily interactions between people and places, reflecting their deep and complex feelings, musical expressions were more dependent on music companies (Ho, 2003). From 1980 to 2009, because the music companies controlled the music industry, the sense of place was shaped by those companies and driven by the market.

The sense of places in 2010-2019. During the period 2010-2019, the distribution of place in song titles was denser and concentrated in the Beijing-Tianjin-Hebei Urban Agglomeration, Yangtze River Delta, Shaanxi, Sichuan, and the Chongqing region (Fig. 5).

Based on the special landforms, traditional musical culture and a strong economic foundation constituted the concentration area of the Shaanxi province. In the Sichuan and Chongqing region, with a background of urban agglomeration and their unique dialect, rich rap songs formed a spatial concentration. The Beijing-Tianjin-Hebei Urban Agglomeration and Yangtze River Delta continue to be economically, culturally intensive, and population-dense regions; they also offer a strong sense of place experience. The keywords in this period pertaining to the sense of place are Beijing, Chongqing, Nanjing, Xi'an, Hangzhou, Jinan, Guangzhou, Lanzhou, and others (Table 5).

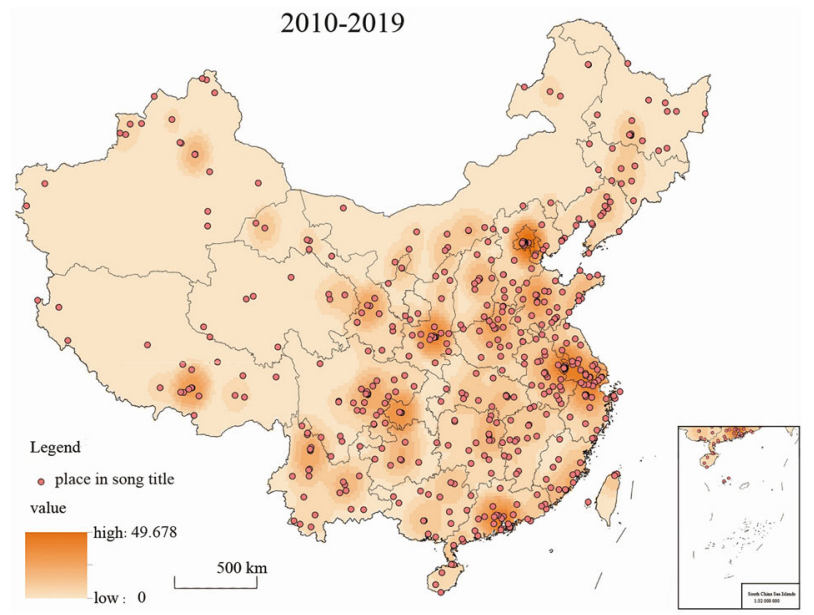

Fig. 5 Kernel density estimation of place in music in 2010-2019. Kernel density estimation of place in music titles from 2010 to 2019 indicates that the darker areas are distributed primarily in Beijing-Tianjin-Hebei Urban Agglomeration, Yangtze River Delta, Shaanxi, Sichuan, and the Chongqing region. These places are referred to often in song titles, forming a cluster.

Table 5 Keywords of sense of place: 2010-2019.

\begin{tabular}{llllll} 
Key words & TF-IDF & Key words & TF-IDF & Key words & TF-IDF \\
\hline Beijing & 142 & beautiful & 33 & Dali & 24 \\
Chongqing & 99 & Shanghai & 32 & Dunhuang & 24 \\
Nanjing & 98 & Chengdu & 30 & Hello there & 18 \\
Xi'an & 80 & Taiyuan & 30 & rain & 17 \\
Hangzhou & 65 & love & 29 & hometown & 15 \\
Jinan & 62 & Suzhou & 29 & taste & 10 \\
Guangzhou & 61 & Goodbye & 29 & Drum Tower & 3 \\
girl & 55 & Qingdao & 28 & High Speed Rail & 3 \\
Lanzhou & 53 & Yangzhou & 28 & subway & 2 \\
story & 52 & winter & 28 & Anheqiao & 1 \\
home & 51 & Xiamen & 27 & Silk Street & 1 \\
Lhasa & 42 & Changsha & 26 & Sanlitun & 1 \\
Lijiang & 40 & Shenzhen & 25 & Line 10 & 1 \\
Zhengzhou & 40 & Taipei & 24 & Shichahai & 1 \\
\hline
\end{tabular}

Before 1979, people tended to settle in a certain place for their entire life. In contemporary China, because people now work primarily in industry and service, and because urban areas are more concentrated and abundant compared to in the periods pre1979, those who live in cities have less contact with rural areas (Jensen, 1998). Additionally, the increasing popularity of online music platforms has diminished the importance of the geographical position. With modern space-time compression (Harvey, 2000), the high level of mobility engenders connections with a wider range of places. In post-modern society, as the influence of new globally popular communication technologies spreads to more cities, the cities are becoming increasingly homogeneous. There are arguments about a sense of place for placelessness. The lyrics of 'Rehe road' describe the change in Nanjing city: Qiulin Crayfish Restaurant changed to a new place, Road 32 still passes through Yejiangmen, the viaduct was demolished, and a new tunnel was repaired, I can't get out of my Yancang Bridge. Great changes to a familiar place can lead to a sense of placelessness, resulting in negative feelings.

As argued by Arefi (1999), the impact of modernity and globalisation weakens the authenticity of places. The by-product concept describes the loss of place as 'non-place' and 'placelessness' and was developed to describe the lack of connection in a physical, cultural, or emotional context. It is acceptable for 
most of us to adapt to the growth of a non-place and placelessness landscape that is monotonous, homogenous, standardised, and inauthentic (Arefi, 1999), and even to generate a sense of place. As indicated by keywords such as 'subway' and 'Line 10', some sense of place is expressed about the railway station and even one specific subway station, as is the case in 'Line 10': Metro Line 10, there is a station called Xitucheng, I get on the subway here every time, with thoughtful thoughts, it's crowded in here, people look like they are in a hurry. The perceived physical characteristics of these places may be the same, while the personal experience of each place is different. Contact and routine exposure to the place generates a sense of place. Thus, although modernisation, urbanisation, and mobility have brought about a lack of place characteristics, they have also made sense with practice and contacts. Moreover, the songs indicate a great nostalgic emotion towards places.

The driving force of sense of place tends to be diversity and individualism in this period. Against an increasingly open and pluralistic backdrop, subjectivity is continually expanding. It is also the result of the development of independent music. The production process of independent music is independent, from recording to publishing by musicians. People no longer describe places in cities by mentioning landmarks that are well known to the public; rather, they tend to nodes within the city that are closely related to their own lives, such as subway stations, bus stops, specific addresses, and so forth. As for Beijing, there are many musical lyrics that refer to the narrower streets and alleyways like the Clock Drum Tower, Shichahai, the Anhe Bridge, and so forth, which are unknown to most audiences. Furthermore, the sense of place that is produced involves one's physical as well as mental experience. The long history and profound diversity of a given culture can increase imagination regarding a place and help to create a multitudinous sense of place. Many songs are about ancient cities like Chang'an (now named Xi'an), which used to be the capital of the Tang Dynasty. With the help of various media, individuals spur subjective associations with and imagination about places (Bork-Hüffer et al., 2016), thereby implying that place may shift away from life practice. The sense of place represented by music in this period of diversity includes the growing impression of 'non-places', feelings towards places that are part of daily routine or imagination, and a sense of 'loss of place' due to changes, homesickness, and so on.

\section{Discussion}

This study identified the content of sense of place in China as indicated by music. Which are the places where we generally experience a sense of place? What is 'sense of place'? These questions and the driving forces are discussed. However, two themes that emerged from the results are the profound change from collective to individual and from a dominant style to a more diverse scenario in terms of sense of place. Sense of place was constructed and continues to be influenced by notions of patriotism, socialism, a market economy, and individualism.

The collective and individual evolution of the sense of place. Our results indicate that sense of place tends to transform from a collective orientation to an individual orientation. During wartime periods or a period of socialistic construction, national concern about the highly significant places can be shared with the collective to strengthen the ideological and political education of people. Pred (1984) believes that the sense of place is not the content of individuals but the collective memory and group sense of place that develops after receiving external social influence. The collective memory of a place is the basis for enhancing the collective sense of place and identity (Ardakani and Oloonabadi,
2011). A place, as well as its 'sense' are constructed by the whole social process, which is invisibly influenced by political ideology (Harvey, 1996). In the Internet era after 2009, people have a freer musical expression that is less affected by society. The emotion tends to be individualistic with the traits of authenticity, sensibility, and infectivity. Recently, though singers tell personal stories, they express concern about high urbanisation rates and socialist market backgrounds of places. This change is rooted in backgrounds with different social conditions such as cultural characteristics, social stability, and economic structures.

East Asian culture emphasises collectivism and group interests (Wagar and Cohen, 2003). It has a group orientation, meaning the interests and values of the country or nation are important, and individual interests can be ignored or even sacrificed when necessary (Hofstede, 1983). The process of modernisation and the influence of Western thought on the sense of place has led to a significant trend from collectivism to individualism.

Music is an important tool for examining the construction of collective memory, and it reflects, integrates, and constructs society's feelings about and recognition of places (Masterson, 2006). Place memory consists of memories related to the history of specific spaces that can be stored individually and collectively. More importantly, a collective sense of place may also include the influence of events and, therefore, result from cultural transmission (Wójcik et al., 2010). The results align with Borer (2006), demonstrating that culture plays a principal role, particularly via collective memory, in shaping the meanings and collective representations of place. Chinese music before 1979 is filled with places of special importance for establishing national identity and indicates the collective awareness underlying the social phenomena. With the background change from turbulence to stability, from difficulty to ease of publishing music, the sense of place conveyed by music is transformed from collective to individual. The songs express personal thoughts, life, emotions, and social experience, and have strong subjective awareness, especially folk and rock music. The overall rebellion against traditional songs' values and the focus on society and history is translated into the specific personal life and emotional experience. Folk creators are freed from the shackles of social responsibility, and values change from collective to the individual.

The dominant style and diverse scenario evolution of the sense of place. With the social background change from relaxation to control and then back to relaxation, sense-of-place trends in this period shift from a dominant style to a more diverse scenario. Patriotism and a sentimental attachment to hometowns were widely inspired in war times, and the sense of place was dominated by collective patriotism. During the period of socialist construction, people's affection for 'place' was controlled by mainstream politics, which showed in their attachment to industrial cities and memorable places. The advent of reform and opening up meant the end of the collectivisation era and the weakening of state power over local society, which leads to individuals quickly regressing from highly collectivised and unified social organisational relationships to free and loose, weak organisational relationships. Undoubtedly, attempts to control musical creation and activities by totalitarian states are verified (Donegani, 2004), and the mainstream sense of place in music is controlled and dominative.

Before the 1970s, there were close links between individuals and places for agricultural production and the main mode of production, and it is formed firmly and deeply with emotions. Owing to the disruption spurred by mobility, both the change in the human-place relationship from 'root' (fixities) to 'route' (mobility) (Di Masso et al., 2019, p. 126) and the two individual states can help to form deep emotional feelings. It is important to mention that 
with the mobility of people and information, there are diverse senses for many places with both the physical and the virtual connection, as indicated by songs. Each place is the focus of a distinct mixture of wider local social relations (Massey, 1994). As Lemos (2008) argues, 'new informational technologies enhance our sense of place because they allow for virtual mobility, whereby a place can be experienced without a physical presence' (p. 104). Moreover, they stimulate imaginary mobility and an illusory sense of place (Bork-Hüffer et al., 2016, p. 132). Nowadays, people's mobility and their forms of mobility are more extensive and diverse. As Edensor (2006) notes, a sense of place is increasingly mobile and extends across space. Based on the nodes and keywords of songs named in places, the sense of place tends to be more abundant.

More places are meaningful to people, and feelings for places are more diverse, abundant, and complex, including not only attachment to and identity with a place but also the disrupted bonds resulting from placelessness. Scholars such as Massey (1994) and Relph (1976) have already augured the phenomenon of place and placelessness under the context of modernity and modernisation; furthermore, they attribute the phenomenon of placelessness to the modernisation and standardisation of city and rural areas, as well as the destruction of older bonds by war and urbanisation. With the high mobility of individuals, most of us connect with non-places such as airports, stations, retail parks, supermarkets, and office blocks. There are different opinions in this study: there is no pure non-place (Trigg, 2017). Places are witnesses to people's practical activities; it is the activities in and contacts with places that are meaningful to individuals in forming a sense of place. A place that lacks physical character is capable of triggering attachment. These standardised places are non-places for most people based on the modern homogenised landscape, but they may be meaningful for some based on significant contacts with the places.

\section{Conclusion}

Music is an important representation of the relationship of people to the land and provides an effective means of expressing the sense of place. This study collected most of the song titles, including place names from 1912 to 2019 in China, to map where people sing and what sense of place is conveyed. The research focused on changes in the mainstream sense of place, considering the background of changes in social contradictions, in order to reflect the social construction and reveal the characteristics of the sense of place.

This paper presents a theoretical framework, illustrated in Fig. 1 , which can be applied in the context of China to explore people's sense of place and understand the influence of sociopsychological processes. The framework emphasises changes in sense of place, shifts from the collective to an individual, and from a dominant style to a more diverse scenario with the transition in the social background. In particular, our results suggest that regional variations in song titles show that characteristics of an individual's sense of place are greatly influenced by the social context. Based on different scenarios, a sense of place can be constructed and applied to different scenarios to improve place identity or satisfaction, even for non-places.

In this study, we used an approach with a considerable historical dimension and focused on the dependence and dialectical transformation of various elements in social change. Exploring the sense of place from the perspective of historical development and social change highlights that people's sense of place is not reflected only in their personal emotional responses; it is also driven by social trends and problems and reflects the basic social conditions. Based on the changes during the historical period, the sense of place represents not only the dominant style and diverse scenario aspects but also the relationships and changes between collectives and individuals. Different understandings of place reveal the role of social backgrounds in constructing a sense of place, thereby illustrating that historical background provides an important lens that can be applied to examine the sense of place through constructive analysis.

However, the scope of this study is limited, and future research could be extended to study specific styles of music. Further, more attention should be paid to the image of cities or provinces, and studies should consider the change in the image of the place from a social-construction perspective. Regarding data collection, although most songs titles containing a place were included in the analyses, there still exist songs that express a sense of place but not in the title and those that are limited by political censorship. Therefore, place references in music titles could be collected more comprehensively or verified using data from different countries. Music can inspire national identity and be closely associated with politics, especially when the state power is turbulent. Although this aspect is not the focus of this research, the political function of music and the changes it brings to society is worth analysis.

\section{Data availability}

The datasets analysed during the current study are available in the openICPSR repository: https://www.openicpsr.org/openicpsr/ workspace?goToPath=/openicpsr/152621\&goToLevel=project

Received: 2 November 2020; Accepted: 18 October 2021; Published online: 24 November 2021

\section{Notes}

1 Hukou is a system of household registration with the power to restrict population mobility and access to state-sponsored benefits for the majority of China's rural population.

2 NetEase Cloud Music (https://y.qq.com/) is a leading interactive music streaming service provider in China. Its focus on discovering and promoting emerging musicians has made NetEase Cloud Music a destination of choice for exploring new and independent music among music enthusiasts in China.

3 QQ Music (https://music.163.com/) is a music-streaming platform affiliated with Tencent. QQ Music has the most comprehensive music library in China and includes content from the three major international labels, namely Universal, Sony, and Warner.

4 Prefecture-level city is the second level of the local administrative region in China;

"Meng" is a special administrative system in Inner Mongolia.

5 http://www.gov.cn/gzdt/2011-03/09/content_1821042.htm

\section{References}

Aizawa A (2003) An information-theoretic perspective of tf-idf measures. Inf Process Manag 39(1):45-65

Ardakani MK, Oloonabadi SSA (2011) Collective memory as an efficient agent in sustainable urban conservation. Procedia Eng 21:985-988

Arefi M (1999) Non-place and placelessness as narratives of loss: rethinking the notion of place. J Urban Design 4(2):179-193

Attali J (1985) Noise: the political economy of music. University of Minnesota Press, Minneapolis

Bennett A (1999) Subcultures or neo-tribes? Rethinking the relationship between youth, style and musical taste. Sociology 33(3):599-617

Bennett A (2017) Music, space and place: popular music and cultural identity. St Martins Press, New York

Bonaiuto M, Carrus G, Martorella H, Bonnes M (2002) Local identity processes and environmental attitudes in land use changes: the case of natural protected areas. J Econ Psychol 23(5):631-653

Bonnin M, Horko K (2013) The lost generation: the rustication of China's educated youth (1968-1980). The Chinese University of Hong Kong Press, Hong Kong

Borer MI (2006) The location of culture: the urban culturalist perspective. City Community 25(2):173-197

Bork-Hüffer T, Etzold B, Gransow B, Tomba L, Sterly H, Suda K, Flock R (2016) Agency and the making of transient urban spaces: examples of migrants in the city in the Pearl River Delta, China, and Dhaka, Bangladesh. Popul Space Place 22(2):128-145 
Brown BB, Perkins DD (1992) Disruptions in place attachment. In: Altman I, Low S eds Place attachment. Plenum, New York, pp. 279-304

Bryant LO (2005) Music, memory, and nostalgia: collective memories of cultural revolution songs in contemporary China. China Rev 5(2):151-175

Burgess JA (1982) Filming the Fens: a visual interpretation of regional character. In: Gold JR, Burgess JA eds Valued environment. George Allen \& Unwin, London, pp. 35-54

Byklum D (1994) Geography and music: making the connection. J Geogr 93(6):274-278

Canova N (2013) Music in French geography as space marker and place maker. Soc Cult Geogr 14(8):861-867

Carney GO (1998) Music geography. J Cult Geogr 18(1):1-10

Carney GO (1987) The sounds of people and places: readings in the geography of American folk and popular music. University Press of America, Boston

Chow K, Healey M (2008) Place attachment and place identity: first-year undergraduates making the transition from home to university. J Environ Psychol 28(4):362-372

Clayton M (2013) The cultural study of music: a critical introduction. Routledge, New York \& London

Connell J, Gibson C (2003) Sound tracks: popular music, identity and place. Routledge, Abingdon

Connell J, Gibson C (2004) World music: deterritorializing place and identity. Prog Hum Geogr 28(3):342-361

Cresswell T (2015) Place: an introduction. Blackwell Publishing, Oxford

Croizier RC (2010) Art in turmoil: the Chinese cultural revolution, 1966-76. Hong Kong University Press, Hong Kong

Devine-Wright P, Howes Y (2010) Disruption to place attachment and the protection of restorative environments: a wind energy case study. J Environ Psychol 30(3):271-280

Di Masso A, Dixon J (2015) More than words: place, discourse and the struggle over public space in Barcelona. Qual Res Psychol 12(1):45-60

Di Masso A, Dixon J, Pol E (2011) On the contested nature of place: 'Figuera's Well', 'The Hole of Shame' and the ideological struggle over public space in Barcelona. J Environ Psychol 31(3):231-244

Di Masso A, Williams DR, Raymond CM, Buchecker M, Degenhardt B, DevineWright P, Von, Wirth T (2019) Between fixities and flows: navigating place attachments in an increasingly mobile world. J Environ Psychol 61:125-133

Dixon J, Durrheim K (2000) Displacing place-identity: a discursive approach to locating self and other. Br J Soc Psychol 39(1):27-44

Donegani JM (2004) Music and politics: the language of music-between objective expression and subjective reality. Raisons Politiques 14(2):5-19

Edensor T (2006) Reconsidering national temporalities institutional times, everyday routines, serial spaces and synchronicities. Eurn J Soc Theory 9(4):525-545

Feldman RM (1996) Constancy and change in attachment to types of settlements. Environ Behav 28(4):61-86

Fung AYH (2007) The emerging (national) popular music culture in China. InterAsia Cult Stud 8(3):425-437

Gibson C, Davidson D (2004) Tamworth, Australia's 'country music capital': place marketing, rurality, and resident reactions. J Rural Stud 20(4):387-404

Greider T, Garkovich L (1994) Landscapes: the social construction of nature and the environment. Rural Sociol 59(1):1-24

Gritzner CF (1978) Country music: a reflection of popular culture. J Popular Cult 11(4):857

Gumprecht B (1998) Lubbock on everything: the evocation of place in popular music. J Cult Geogr 18(1):61-81

Gustafson P (2009) Mobility and territorial belonging. Environ Behav 41(4):490-508

Halbwachs M (1992) On collective memory. University of Chicago Press, New York

Harvey D (1996) Justice, nature and the geography of difference. Blackwell Publishers, Cambridge

Harvey D (2000) Time-Space compression and the postmodern condition. Polity Press, Cambridge

Ho WC (2000) The political meaning of Hong Kong popular music: a review of sociopolitical relations between Hong Kong and the People's Republic of China since the 1980s. Popular Music 19(3):341-353

Ho WC (2003) Between globalisation and localisation: a study of Hong Kong popular music. Popular Music 22(2):143-157

Hofstede G (1983) Dimensions of national cultures in fifty countries and three regions. Expiscations Cross-Cult Psychol 15(13):335-355

Holm DL (1984) Folk art as propaganda: the yangge movement in Yan'an. In: McDougall BonnieS (Ed) Popular Chinese literature and performing arts in the People's Republic of China, 1949-1979. University of California Press, Berkeley, pp. 3-35

Hudson R (2006) Regions and place: music, identity and place. Prog Hum Geogr 30(5):626-634

Inalhan G, Finch E (2004) Place attachment and sense of belonging. Facilities 22(5-6):120-128

Jenkins A, Croitoru A, Crooks AT, Stefanidis A (2016) Crowdsourcing a collective sense of place. PLoS ONE 11(4):1-20
Jensen J (1998) The nashville sound: authenticity, commercialization, and country music. Vanderbilt. University Press, Nashville

Kearney D (2010) Listening for geography: the relationship between music and geography. Chimera 25:47-76

Kearney D (2009) Towards a regional understanding of Irish traditional music. University College Cork, Ireland

Keller SM (2007) Why is music so ideological, and why do totalitarian states take it so seriously? A personal view from history and the social sciences. J Musicol Res 26(2-3):91-122

Kim D, Seo D, Cho S, Kang P (2019) Multi-co-training for document classification using various document representations: TF-IDF, LDA, and Doc2Vec. Inf Sci 477:15-29

Kong L (1995) Popular music in geographical analyses. Prog Hum Geogr 19:183-198

Kyle G, Chick G (2007) The social construction of a sense of place. Leis Sci 29(3):209-225

Lee RG (1972) The social definition of outdoor recreation places. In: Burch Jr WR, Cheek NH, Taylor L (Eds.) Social behavior, natural resources, and the environment. Harper and Row Publishers, New York, pp. 68-84

Lei WM, Wang Y (2011) Fangge 90 Nian: Liuxing Hongge Jingxuan. Anhui Literature \& Art Publishing Company, Hefei

Lemos A (2008) Mobile communication and new sense of places: a critique of spatialization in cyberculture. Galáxia. Rev Programa Pós-Grad Comun Semiót 18(16):91-108

Lewicka M (2011) Place attachment: how far have we come in the last 40 years? J Environ Psychol 31(3):207-230

Leyshon A, Matless D, Revill G (1995) The place of music: music, space and the production of place. Guilford, New York

Leyshon A, Matless D, Revill G (1998) The place of music New York. Guilford Press, London

Li DF (2008) Interpretation of canonization: for example of piano concerto Yellow River. Musicol China 3:28-30

Lin T-C (2019) Collective memory and sense of place in Taiwan's Hakka music: a case study of selected collections of Hakka songs. Global Hakka Stud 12:131-174

Liu C, Cai XM (2016) Noise up! A cultural geographical analysis of live music in Guangzhou. Sci Geogr Sinica 36(6):871-878

Liu C, Cai XM (2014) Performing Guangzhou and Guangzhou Ren: analysing popular music in Guangzhou. Soc Cult Geogr 15(7):769-785

Liu JH, Hilton DJ (2005) How the past weighs on the present: social representations of history and their role in identity politics. $\mathrm{Br} \mathrm{J}$ Soc Psychol 44(4):537-556

Liu JZ (2010) A critical history of new music in China. The Chinese University Press, Beijing

Long P, Collins J (2012) Mapping the soundscapes of popular music heritage In: Roberts L (Ed.) Mapping cultures. Palgrave Macmillan, London, pp. $144-159$

Ma Y, Deng Y (1995) On music and geographical environment. Hum Geogr 1995(4):52-55

Marchetti G (2009) Hong Kong film, Hollywood and new global cinema: no film is an island. Asian J Soc Sci 37(6):970-971

Massey D (1994) Space, place and gender. University of Minnesota Press, Minneapolis

Masterson DM (2006) The chrysanthemum and the song: music, memory and identity in the South American Japanese diaspora/strangers in the ethnic homeland: Japanese Brazilian return migration in transnational perspective. Am Anthropol 108(2):397

Milburn K (2019) Rethinking music geography through the mainstream: a geographical analysis of Frank Sinatra, music and travel. Soc Cult Geogr 20(5):730-754

Misztal B (2003) Theories of social remembering. McGraw-Hill Education, London

Morgan J (2001) Popular culture and geographic education. Int Res Geogr Environ Educ 10(3):284-297

O'Connell JM (2011) Music in war, music for peace: a review article. Ethnomusicology 55(1):112-127

Peng J, Zhao S, Liu Y, Tian L (2016) Identifying the urban-rural fringe using wavelet transform and kernel density estimation: a case study in Beijing City, China. Environ Model Softw 83:286-302

Perris A (1983) Music as propaganda: art at the command of doctrine in the People's Republic of China. Ethnomusicology 27(1):1-28

Pocock DCD (1981) Place and the novelist. Trans Inst Br Geogr (New Ser) 6(3):337-347

Pred A (1984) Place as historically contingent process: structuration and the timegeography of becoming places. Ann Assoc Am Geogr 74(2):279-297

Qiao JZ (1998) The geographical features of traditional Chinese music and Chinese music construction of geography. J Cent Conserv Music 3:3-9

Relph E (1976) Place and placelessness. Pion, London

Revill G (2000) Music and the politics of sound: nationalism, citizenship, and auditory space. Environ Plan D 18(5):597-613 
Revill G (2005) Vernacular culture and the place of folk music. Soc Cult Geogr 6(5):693-706

Roberts AF (2001) 'Break the silence': art and HIV/AIDS in KwaZulu-Natal. Afr Arts 34(1):37-95

Roccas S, Sagiv L, Schwartz S, Halevy N, Eidelson R (2008) Toward a unifying model of identification with groups: integrating theoretical perspectives. Personal Soc Psychol Rev 12(3):280-306

Ryden KC (1999) Writing the midwest: history, literature, and regional identity. Geogr Rev 89(4):511-532

Salton G, Buckley C (1988) Term-weighting approaches in automatic text retrieval. Inf Process Manag 24(5):513-523

Stedman RC (2003) Is it really just a social construction? The contribution of the physical environment to sense of place. Soc Nat Resour 16(8):671-685

Street J (2003) "Fight the Power": the politics of music and the music of politics. Government Oppos 38(1):113-130

Stokowski PA (2002) Languages of place and discourses of power: constructing new senses of place. J Leis Res 34(4):368-382

Thompson DJ (2006) Searching for silenced voices in Appalachian music. GeoJournal 65(1-2):67-78

Trigg D (2017) Place and non-place: a phenomenological perspective. In: Janz B (eds) Place, space and hermeneutics. Springer, Berlin, pp. 127-139

Tuan Y-F (1977) Space and place: the perspective of experience. The University of Minnesota Press, Minnesota

Tuohy S (2001) The sonic dimensions of nationalism in modern China: musical representation and transformation. Ethnomusicology 45(1):107-131

Van Zaanen M, Kanters P (2010) Automatic mood classification using TF*IDF based on lyrics. In Downie J, Veltkamp R (Eds.), 11th International Society for Music Information Retrieval Conference. TiCC, pp. 75-80

Wagar BM, Cohen D (2003) Culture, memory, and the self: an analysis of the personal and collective self in long-term memory. J Exp Soc Psychol 39(5):468-475

Wang YH (2009) History of Chinese contemporary music. People's Music Publishing House, Beijing

Williams DR (2002) Leisure identities, globalization, and the politics of place. J Leis Res 34(4):351-367

Wójcik A, Bilewicz M, Lewicka M (2010) Living on the ashes: collective representations of Polish-Jewish history among people living in the former Warsaw Ghetto area. Cities 27(4):195-203

Wood LA, Gritzner CF (1990) A million miles to the city: county music's sacred and profane images of place. In: Zonn L (ed) Place images in the media: portrayal, experience and meaning. Rowman \& Littlefield, Maryland, p 231-254

Yano C (2003) Tears of longing: nostalgia and the nation in Japanese popular song. Harvard University Press, Cambridge

Zukin S (1991) Landscapes of power: from Detroit to Disney World. University of California Press, Berkeley

\section{Acknowledgements}

The research was supported by the National Natural Science Foundation of China (grant numbers: 42071175, 42171231, and 42101218), MOE (Ministry of Education in China) Humanities and Social Sciences Foundation (grant numbers: 21YJC790131, 21YJAZH030).

\section{Competing interests}

The authors declare no competing interests.

\section{Ethical approval}

This article does not contain any studies with human participants performed by any of the authors.

\section{Informed consent}

This article does not contain any studies with human participants performed by any of the authors.

\section{Additional information}

Correspondence and requests for materials should be addressed to Zhenfang Huang or Xu Huang.

Reprints and permission information is available at http://www.nature.com/reprints

Publisher's note Springer Nature remains neutral with regard to jurisdictional claims in published maps and institutional affiliations.

cc (i) Open Access This article is licensed under a Creative Commons Attribution 4.0 International License, which permits use, sharing, adaptation, distribution and reproduction in any medium or format, as long as you give appropriate credit to the original author(s) and the source, provide a link to the Creative Commons license, and indicate if changes were made. The images or other third party material in this article are included in the article's Creative Commons license, unless indicated otherwise in a credit line to the material. If material is not included in the article's Creative Commons license and your intended use is not permitted by statutory regulation or exceeds the permitted use, you will need to obtain permission directly from the copyright holder. To view a copy of this license, visit http://creativecommons.org/ licenses/by/4.0/.

(C) The Author(s) 2021 